\title{
Potent Acrylamide Determination in Food Products Using Ion-Selective Electrode Technique
}

\author{
Sabry Khalil ${ }^{1, *}$, Alaa El-Beltagy ${ }^{1}$ and Mohamed El-Sharnouby ${ }^{2}$ \\ 1 Department of Food Nutrition Science, College of Science, Taif University, P.O. Box 11099, \\ Taif 21944, Saudi Arabia; aelbeltagu@Tu.edu.sa \\ 2 Department of Biotechnology, College of Science, Taif University, P.O. Box 11099, Taif 21944, Saudi Arabia; \\ m.sharnouby@tu.edu.sa \\ * Correspondence: Sabry@Tu.edu.sa or S_Khalil_99@Yahoo.co.uk
}

Citation: Khalil, S.; El-Beltagy, A.; El-Sharnouby, M. Potent Acrylamide Determination in Food Products

Using Ion-Selective Electrode

Technique. Membranes 2021, 11, 645 https://doi.org/10.3390/

membranes11080645

Academic Editor:

Konstantin Mikhelson

Received: 5 July 2021

Accepted: 16 August 2021

Published: 23 August 2021

Publisher's Note: MDPI stays neutral with regard to jurisdictional claims in published maps and institutional affiliations.

Copyright: (C) 2021 by the authors. Licensee MDPI, Basel, Switzerland. This article is an open access article distributed under the terms and conditions of the Creative Commons Attribution (CC BY) license (https:/ / creativecommons.org/licenses/by/ $4.0 /)$.

\begin{abstract}
A potent selective acrylamide liquid sensor based on the reaction of acrylamide with 2-(5Bromo-2-pyridylazo)-5-[N-n-Propyl-N-(3-Sulfopropyl) amino] aniline reagent is successfully designed. The characteristics slope $\left(52.33 \mathrm{mV} /\right.$ decade), linearity usable range from $1.0 \times 10^{-7}-1.0 \times 10^{-1}$ molar, limit of detection $\left(1.6 \times 10^{-8}\right)$ molar, selectivity attitude to several inorganic cations, amino acids and sugars, time of response ( $8 \mathrm{~s})$, lifetime (four months), $\mathrm{pH}$ effect on the electrode potential and the basic validation parameters were studied. The desirable $\mathrm{pH}$ applicable range was 3.0-6.5, and the restraint of the developed sensor is independent on this working $\mathrm{pH}$ range. The deployed electrode was effectively applied for rapid inexpensive analysis of acrylamide cations in food products with comparison to high-performance liquid chromatographic method and the results were agreeable with each other. The obtained data by the suggested electrode were treated statistically and compared with the various recently published acrylamide sensors.
\end{abstract}

Keywords: ion-associate complexe; membrane sensor; acrylamide detection; food product samples

\section{Introduction}

Scientists concert that acrylamide in food also has the prospective to litigate cancer in humans. We put forward that the consumed amount of acrylamide (AA) is decreased, as protection. Modern feedback displays that acrylamide is formed during the boiling/sterilizing of foods containing starch, like bread and potatoes. It is not intentionally added to foods; it is a natural second product of the cooking method, and always found in our food. Laboratory studies display that acrylamide can cause cancer in humans. The consistency of acrylamide in addressed food is presented by the chemical combination between amino acid asparagine and glucose. In addition to methionine, other amino acids like cysteine, arginine, alanine, aspartic acid, glutamine, threonine and valine have also produced acrylamide [1].

Acrylamide is formed during the boiling/sterilizing of foods containing starch, such as bread and potatoes.

The recent enactment will demand food business workers to introduce a site simple, practical proceedings to handle acrylamide within their food safety administration systems $[2,3]$. Food quality monitoring and delightfulness are of global interest for both the food industry and consumers, which has put a lot of effort to recognize and consummation gauges to decrease acrylamide levels in food. This comprises developing orientation on strategies to frontier acrylamide construction in a diversity of foods and processes.

Hence, it is needful to improve such a frugal, sensitive, specified and quick system, which can estimate acrylamide content in thermally processed foods, ion-selective membrane sensors as simple, quick, mobile, little and economic tools can be utilized to evaluate metal cations [4-6]. 
Several traditional standard analytical techniques have been deployed to detect acrylamide concentration including chromatography, mass spectrometry and chromatographymass spectrometry. Liquid chromatography-mass spectrometry was utilized to estimate acrylamide in food [7]. Other outright gas chromatography-mass spectrometry was used to estimate acrylamide apart in food and coffee powder [8,9]. Recently, enzyme-linked immunosorbent assay (ELISA) [10] and capillary electrophoresis [11] have also been utilized for the determination of acrylamide.

Anywise, these techniques have the disadvantage of tedious pretreatment samples, long estimation time, high expenses and high practical adjustment validations. The electrochemical analysis is vastly concerned by most scientists in order for its advantages of being quick, simple and economic, and ability to be utilized to recognize on-site searches [12]. Therefore, electrochemical techniques have been widely utilized in biological [13-24] and environmental analysis [25-32].

For the past few years, many types of research are reported as electrochemical sensors for acrylamide detection [1,33-44], although most of them just focused on improving the sensitivity, stability and other performance of the electrochemical analysis.

Despite the recently reported methods having high sensibility and providing accurate and precise results, some tedious complications were found in their utilities. Therefore, they are not suitable for routine and on-site analysis. Potentiometric measurements depend on the nominated electrode, are very plain, and display several superior validations, such as fluent sample conditions, quick restraint, very eclectic, expanding linearity range of concentration, simple types of equipment with a quite low limit of detection, completed in viscous, colored, and/or turbid solutions, and being economic. However, recently specified reagents belonged to heterodiazo dyes that perform strongly, and stabilized ion-associate with many active cations were created to estimate them in foodstuff, real environmental samples and pharmaceutical formulations by new, very selective and sensitive spectrophotometric determinations [45-48].

The cited ligand 2-(5-Bromo-2-Pyridylazo)-5-[N-n-Propyl-N-(3-Sulfopropyl) amino] aniline [BrPPSAA] (Figure 1) is firstly prepared as described before [49]. It is a tridentate ligand, which has super sensitivity beside a very good selectivity coefficient for some cations. It forms an ion-associate complex with some different cations like (Co, $\mathrm{Ni}, \mathrm{Zn}$, $\mathrm{Cu}, \mathrm{Fe}$ ) at the optimum $\mathrm{pH}$ range of 3.0-4.5 with maximum absorption approximately at $602 \mathrm{~nm}$; the molar absorptivity of the formed complexes is very high. Generally, the employed reagent 5-Br-PPSAA is commercially available at reasonable costs. So, we decided to use its practical utility for the construction of acrylamide membrane sensors.

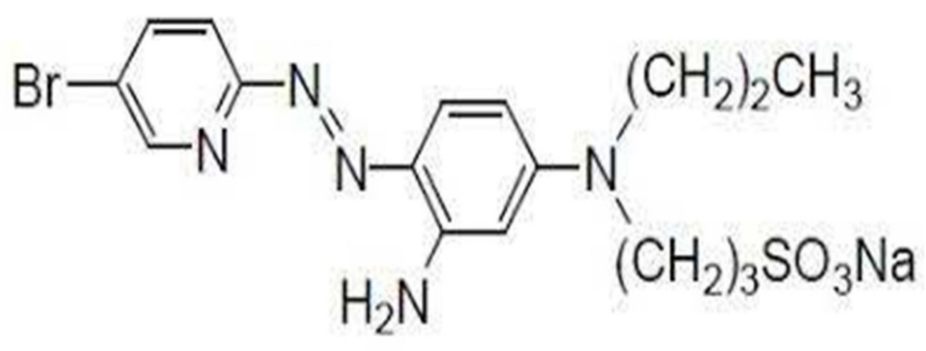

Figure 1. Structure of the reagent [BrPPSAA].

The present work describes the construction and evaluation of a newly acrylamide membrane electrode. The active components in a matrix polyvinyl chloride (PVC) selective electrode are the acrylamide-reagent ion-associate complex. The characteristic slope, usable and quick restraint for acrylamide cations was displayed by the developed sensor within the linearity range $1.0 \times 10^{-7}-1.0 \times 10^{-1} \mathrm{M}$, the detection limit $\left(1.6 \times 10^{-8}\right) \mathrm{M}$, the selectivity study toward several cations, the lifespan (120 days), the restraint time (8 s), the $\mathrm{pH}$ effect on the electrode potential and the basic validation parameters were studied. The applicable range of $\mathrm{pH}$ was 3.0-6.5, and the restraint of the designed sensor is independent of $\mathrm{pH}$ 
in such working range. The electrode is effectively applied to determine the acrylamide concentration in foodstuff. The obtained results by the nominated sensor were treated statistically, and compared with the other different recently reported acrylamide sensors.

\section{Materials and Methods}

\subsection{Sample Products, Materials and Chemicals}

Chlorides of calcium, magnesium and/or copper, ammonium and sodium hydroxide, Polyvinylchloride (PVC), acrylamide99+\%, alanine, D-fructose, and TEHP; [tri-(2-ethyl hexyl) phosphate] were Aldrich products. Hydrochloric acid, tetrahydrofuran, and Lcystine from Merck (Kenilworth, NJ, USA). Arginine, glycine and glucose were from Fluka (Buchs, Switzerland).

The cited ligand [BrPPSAA] was purchased from local chemical stores in Egypt. Foodstuff samples containing acrylamide (coffee substitutions, potato chips, crispbread, French fries, cereal based foods and toast) were obtained from local food stores in Egypt and Saudi Arabia.

\subsection{Preparation of Stock Solutions}

Stock solutions of $\mathrm{Ca}^{+2}, \mathrm{Mg}^{+2}$, and $\mathrm{Cu}^{+2}$ of 0.1 molar solutions were prepared by weighing and dissolving the calculated quantities of each one in bidistilled $\mathrm{H}_{2} \mathrm{O}$. Solutions of $10^{-7}-10^{-1}$ molar were prepared by dilution.

\subsection{Sample Preparation for the Estimation of Acrylamide Cations}

Foodstuff samples (coffee substitutions (dry and soluble), potato chips, crispbread, French fries, cereal-based foods and toast) were selected for analysis, Naturally, raw foods are not toxic. The collected samples were brought to the laboratory, then mashed/ground. One gram of each sample was mixed with $100 \mathrm{~mL}$ of distilled water, and then the $\mathrm{pH}$ was adjusted to 4.5 using $1 \mathrm{M} \mathrm{HCl}$ and the mixture stirred at $25^{\circ} \mathrm{C}$ for $30 \mathrm{~min}$. applying a magnetic stirrer. The stirred mixture was filtered through Whatman 1 , stored in dark bottles at refrigerator for acrylamide determination (within $24 \mathrm{~h}$ ), and then equivalent quantities $(200,350,375,225,120,175$, and $150 \mathrm{mg}$ of them, respectively) were taken for analysis.

The foodstuff samples were further analyzed by the high-performance liquid chromatography (HPLC) method, described before [50] for quantification, and the obtained results were compared with those of the present method.

\subsection{Fabrication of the Selective Sensor}

The selective membrane fabrication was developed as mentioned earlier [51]. It comprises a column electrode of Teflon mutable and a body filled with a liquid membrane " $+\mathrm{Ag} / \mathrm{Ag} \mathrm{Cl}$ ", an internal reference sensor $/ 1.0 \times 10^{-2} \mathrm{~mol} \mathrm{~L}^{-1}$ acrylamide solution, $1.0 \times 10^{-2} \mathrm{~mol} \mathrm{~L}^{-1} \mathrm{KCl}$ (internal reference solution). The complex \{Acrylamide[BrPPSAA]\}, plasticizer (TEHP) and the polyvinyl chloride (PVC) were finely grounded, then tetra hydro furan was added as a volatile solvent. To the flat end of polyvinyl chloride tubing an appropriate diameter disk was cut and glued with tetrahydrofuran. The electrode body was completed with $0.001 \mathrm{M}$ of the acrylamide solution. The electrode was conditioned by dipping it for $24 \mathrm{~h}$ in $0.01 \mathrm{M}$ acrylamide solution and stayed in a comparable solution.

\subsection{Active Component of Liquid-Sensor Layer}

The complex \{Acrylamide[BrPPSAA]\} is the active constituent is formed by the reaction between the cited ligand [BrPPSAA] and acrylamide which contains a reactive electrophilic double bond and an amide group, which can also react. It exhibits both weak acidic and basic properties. In an acidic medium, the electron withdrawing carboxamide group activates the double bond, which as a consequence reacts readily with nucleophilic regent [BrPPSAA]. The maximum absorption of free (5-Br-PSAA and acrylamide) are at 457 and $273 \mathrm{~nm}$, respectively. The UV-visible absorption spectrum of the acrylamide-5-BrPSAA ion-associate complex was measured in the range of $300-700 \mathrm{~nm}$ at the optimum 
acidic $(\mathrm{pH}=6)$. A maximum absorbance of the complex is observed approximately at $602 \mathrm{~nm}$ where the free reagent has minimum absorbance.

\subsection{The Potential Layer Conditioned}

The selectivity and sensitivity of the ion-selective electrode are deeply affected by the composition and the nature of additives employed. Therefore, the influence of various membrane compositions on the response characteristics of the fabricated acrylamide membrane electrode were studied to optimize the best composition of the nominated electrode. Plasticizer is the interesting constituent of the membrane sensor and has effects on the mobility, the state of ionophore molecules and dielectric constant of membrane. It did not only enhance the workability of the membranes, but also improved the working concentration range, stability and life span of the electrode. Therefore, by taking constant amount of PVC (0.44 g), by changing the ratio between the compound [Acrylamide( BrPPSAA)] and the plasticizer TEHP as follows: [ $(0.04 \mathrm{~g}, 0.52 \mathrm{~g}),(0.05 \mathrm{~g}, 0.51 \mathrm{~g}),(0.06 \mathrm{~g}, 0.50 \mathrm{~g}),(0.01 \mathrm{~g}$, $0.55 \mathrm{~g}),(0.02 \mathrm{~g}, 0.54 \mathrm{~g}),(0.03 \mathrm{~g}, 0.53 \mathrm{~g})$, respectively]. The mixture was blended to provide the ion-selective sensor strata. A Teflon tube with an electrode of $\mathrm{Ag} / \mathrm{AgCl}$ was completed with the recently conditioned mixture, and then put into a gel by heating at a temperature of $375 \mathrm{~K}$ for $25 \mathrm{~min}$. The membrane sensor was immersed for $2 \mathrm{~h}$ in $10^{-3} \mathrm{M}$ acrylamide solution after cooling.

\subsection{Measurements of EM F}

An Orion 90-00-01 solution including $0.55 \mathrm{M}$ potassium chloride, $1.5 \mathrm{M}$ potassium nitrate, one $\mathrm{ml}$ of $40 \%$ formaldehyde and $0.05 \mathrm{M}$ sodium chloride was applied to fill the stabilized bridge of the reference electrode. An Orion 90-02 reference electrode was utilized with a mechanical stirrer to give an accuracy of $0.1 \mathrm{mV}$ at laboratory conditions for recording the EMF of the acrylamide electrode system.

\section{Results}

The interesting basic analytical validations of the fabricated acrylamide ion-selective sensor were investigated to present its important value in food analysis. The selectivity study, detection limit, the characteristics slope, response time and influence of $\mathrm{pH}$ on the sensor's potential were studied.

\subsection{Calibration Curves}

Figure 2 presented the calibration curve of acrylamide electrode The acrylamide sensor's specific slope is $52.33 \mathrm{mV} /$ decade, the detection limit is $1.6 \times 10^{-8} \mathrm{M}$ as determined from the intersection of the two extrapolated segments of the calibration graph, and the measuring linearity usable range is $1.0 \times 10^{-7}-1.0 \times 10^{-1} \mathrm{M}$ (with correlation coefficient $r^{2}=0.998$ ). Table 1 presented the analytical validation parameters of the suggested acrylamide sensor.

Table 1. Analytical validation parameters of the developed acrylamide sensor.

\begin{tabular}{lc}
\hline Specific Slope, $\mathrm{mV} /$ decade & 52.33 \\
Intercept $/ \mathrm{mV}$ & $-46.40 \pm 0.30$ \\
Limit of detection $/ \mathrm{mol} \mathrm{dm}^{-3}$ & $1.60 \times 10^{-8}$ \\
Linearity range $/ \mathrm{mol} \mathrm{dm}^{-3}$ & $1.0 \times 10^{-7}-1.0 \times 10^{-1}$ \\
Response time $/ \mathrm{s}$ & 8 \\
Lifetime/d & 120 \\
$\mathrm{pH}$ working range & $3.0-6.5$ \\
\hline
\end{tabular}




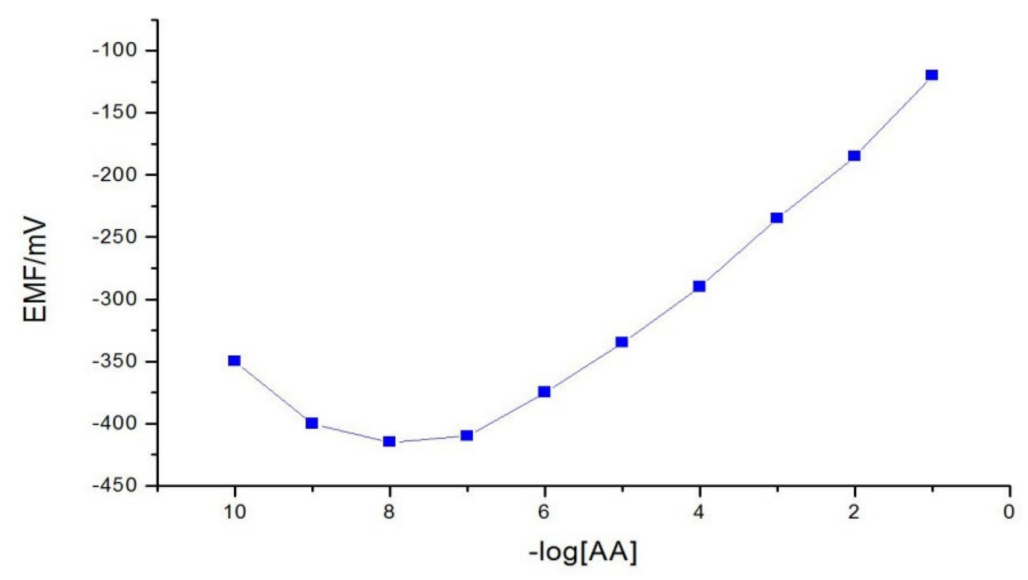

Figure 2. The suggested Acrylamide calibration curve in the linear concentration range $10^{-7}-10^{-1} \mathrm{M}$.

\subsection{Interference Study}

The selectivity behavior of the acrylamide membrane sensor with reference to interfering metal cations and compounds like amino acids or sugars which compete with the precursors in food to reduce acrylamide formation, based on the inhibition of the intermediate compounds formed in acrylamide formation was examined by the separate solution mode or by the MPM, (matched potential mode in the case of sugars and amino acids), reported before [52] using the equations

$$
\log K^{\text {pot }}{ }_{i j}=\left[\left(E_{2}-E_{1}\right) / S\right]-\left(1+Z_{i} / Z_{j}\right) \log a_{i}
$$

where, ai is the AA activity, $E_{1}$ and $E_{2}$ are the potentials of AA and interfering species, zi and zj are the charges of AA and interfering species, respectively, and $S$ is the slope of the sensor calibration plot. By employing the separate solution mode, at the value of EMF with acrylamide cations concentration $0.001 \mathrm{M}$ and, the potential $-160 \mathrm{mV}$. With respect to the matched potential method is employed for interfering compounds (sugars and amino acids depending on the activity ratio of AA (ai) and interfering compound (aj), $\mathrm{M}$ refer to the interfering species, the equation is:

$$
\mathrm{K}^{\text {pot }} \mathrm{AA} / \mathrm{M}=\mathrm{ai} /(\mathrm{aj})
$$

\subsection{Dynamic Response Time of the Acrylamide Sensor}

The response time of the nominated ion-selective electrode is a very interesting parameter for analytical applications. In this research, the practical restraint time was registered by changing the acrylamide cations concentration in solution, over a concentration range from $1.0 \times 10^{-7}-1.0 \times 10^{-1} \mathrm{M}$, and the results are depicted in Figure 3. As presented, the acrylamide sensor reached its equilibrium response over the whole concentration range, in a very short time $(8 \mathrm{~s})$. This is possible due to the quick interchange kinetics of forming and decomposing the ion-associate complex of acrylamide cations with the reagent [BrPPSAA] on the test solution-membrane interface.

\subsection{Influence of $p H$ on the Sensor Potential}

The dependence of the electrode potential on $\mathrm{pH}$ was examined by recording the sensor potential, where AA is involved in acid-base equilibrium, and thus the concentration of the cationic form of AA changes with $\mathrm{pH}$ resulting in changes in the sensor potential.

Some drops of hydrochloric acid or sodium hydroxide were added to the $0.001 \mathrm{M}$ acrylamide cations sample understudying. After each addition, the $\mathrm{pH}$ was registered, the electromotive force; and EMF of the AA electrode system/reference sensor was recorded after the stabilization of the electrode restraint. The $\mathrm{pH}$ influence on the EMF is presented in Figure 4. Lowering and higher than the working $\mathrm{pH}$ range (3.0-6.5), the potential reduces at higher values $(-162$ at $\mathrm{pH} 7.0,-171$ at $\mathrm{pH} \mathrm{8.0,} \mathrm{and}-190$ at $\mathrm{pH} 10)$ which is attributed to 
the hydrolysis of acrylamide cations or the incompleteness of the complexation reaction. At lower $\mathrm{pH}$ values, the potential increases $(-150$ at $\mathrm{pH} 2.5$, and -157 at $\mathrm{pH} 2.0$ ) because of the sensor responses to hydronium ions and acrylamide cations.

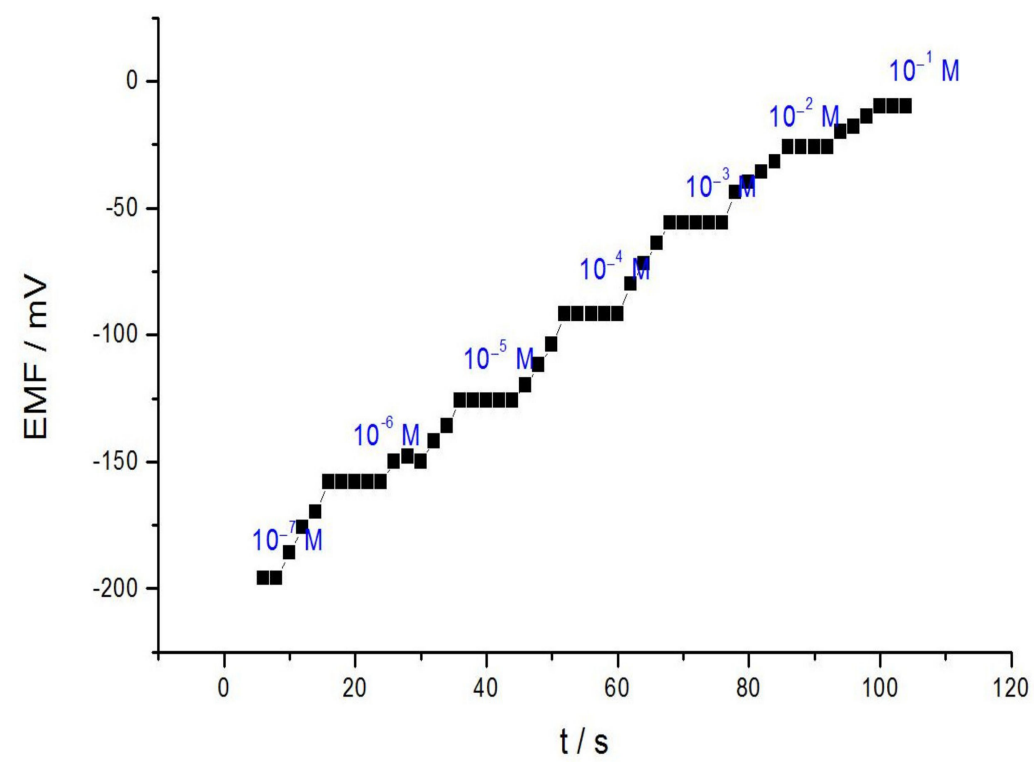

Figure 3. Response time of the suggested sensor for step changes in the concentration range of acrylamide.

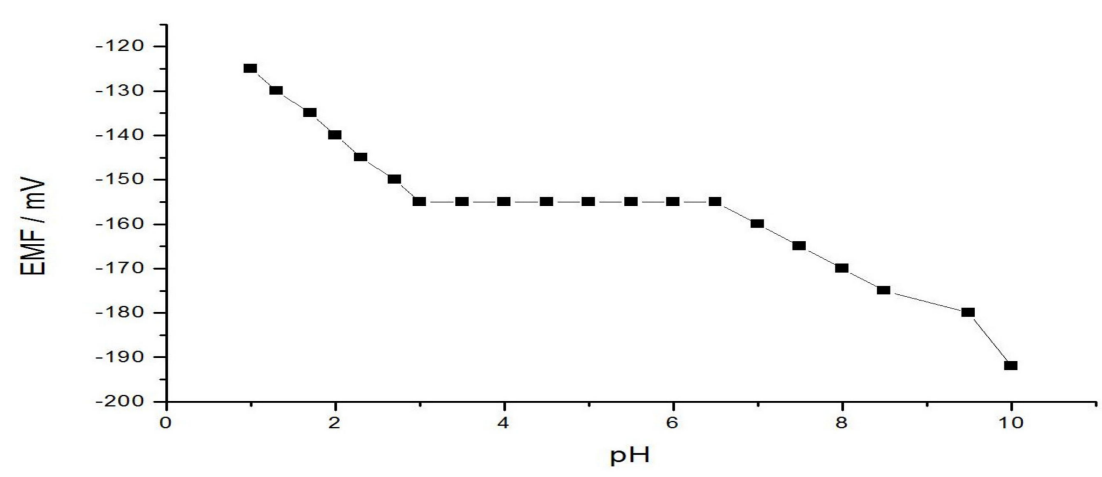

Figure 4. Effect of the electrode response on the $\mathrm{pH}$ in $10^{-3} \mathrm{M}$ acrylamide solution.

\subsection{Lifespan of the AA Selective Electrode}

The duration-time of the nominated acrylamide electrode was examined by recording the specific slope of the sensor kept at $4{ }^{\circ} \mathrm{C}$. For at least six months the systematic realizations were carried out once a week, in recently conditioned solutions in a regular mode. Repeatable, constant and reproducible measurements were attained after four months. A tenuous decrement was seen in the slope of the electrode by $1.0 \mathrm{mV}$ decade $^{-1}$ from $52.33-51.33 \mathrm{mV} /$ decade accompanied by an increment in the detection limit. Afterward, the slope of the electrode reduced progressively, while the limit of detection is increased from 46.28 to $42.15 \mathrm{mV} /$ decade and $1.3 \times 10^{-7}$ to $2.5 \times 10^{-6} \mathrm{M}$, respectively. This possibly emerges from the nomination of the sensor constituents. Therefore, the lifetime of the electrode is about four months, related to the basis of the obtained data.

\subsection{Acrylamide Estimation in Food Product Specimen}

The estimation of acrylamide cations in food product specimen was examined using the suggested ion-selective sensor to test its analytical practical utilities. The techniques standard additions and the calibration curve were employed. The amounts of acrylamide in the samples were computed from predetermined calibration plots. The resulting data by 
the suggested mode were in good compatibility with the HPLC reference method for all food product samples understudying.

\section{Discussion}

The optimum, real value of the Nernstian slope is $59.1 / \mathrm{n}$ (mV/decade) [53]. It is deliberated from the slope curve between the log concentrations of standard solution (M) with the potential recorded in $(\mathrm{EMF} / \mathrm{mV})$. The specific Nernstian slope is a very interesting factor to distinguish selective electrodes that are adequately employed in the estimations. In this research, the Nernstian value was $52.33 \mathrm{mV} /$ decade as presented in Figure 2, which is closely agreed with the ideal value. It means that the potential changes with $52.33 \mathrm{mV} /$ decade if the AA concentration changes with one order of magnitude. This value proves that the eclectic sensor is still workable to apply in acrylamide analysis due to the pliable value of the specific Nernstian slope is $52.33 \mathrm{mV} /$ decade.

Among the various membrane compositions that contains of $0.01 \mathrm{~g}$ compound [acrylamide(BrPPSAA)] with a mixture of, $0.55 \mathrm{~g}$ TEHP, and $0.44 \mathrm{~g}$ PVC has the best behavior of the membrane electrode (the calibration curve (Figure 2)). It showed a good Nernstian response with a slope of $52.33 \mathrm{mV} /$ decade for four replicate measurements in the usable rectilinear usable range of $1.0 \times 10^{-7}-1.0 \times 10^{-1} \mathrm{M}$ with a very low limit of detection $\left(1.6 \times 10^{-8} \mathrm{M}\right)$, as determined from the intersection of the two extrapolated segments of the calibration graph.

In this work, some different foreign metal cations and compounds were investigated. The values summarized in Table 2 revealed that the suggested acrylamide ion-selective electrode is highly selective towards acrylamide cations in the presence of those interfering metal cations, and compounds (sugars and amino acids) under test. As was shown from the resulting data, the investigated interfering metal cations $\left(\mathrm{Ca}^{2+}, \mathrm{Mg}^{2+}\right.$, and $\left.\mathrm{Cu}^{2+}\right)$ may be interfering. Thus, the interference can be eliminated by adding lactic acid before the addition of the cited reagent, and EDTA was added after the formation of the acrylamide ion-associate complex as masking agents in the suggested method, and then the mixture was again heated at $95^{\circ} \mathrm{C}$ for $5 \mathrm{~min}$. The selectivity behavior is improved because the formed metal complexes are decomposed by the addition of EDTA. In the case of sugars and amino acids, the high selectivity is in relation to the difference in polarity and lipophilic nature of their molecules relative to acrylamide. The mechanism of selectivity is basically based on the stereospecificity and electrostatic environment, and counts on how much fitting is available between the locations of the lipophilicity sites in two competing species in the bathing solution side and those present in the receptor of the ion-exchanger [54]. None of the understudying compounds had a noticeable effect on the potentiometric responses of the nominated sensor towards acrylamide cations. The surprise of the high selectivity of the suggested electrode over the other tested foreign metal cations and compounds, most probably resulting from the high affinity of the carrier molecules for acrylamide cations.

Table 2. The selectivity coefficients (K) values of AA membrane sensor (reference electrode $\mathrm{Ag} / \mathrm{AgCl}$ ).

\begin{tabular}{llll}
\hline \multicolumn{1}{c}{$\mathbf{K}$} & $\mathbf{E}_{\mathbf{i}}=\mathbf{E}_{\mathbf{j}}$ & $\mathbf{a}_{\mathbf{i}}=\mathbf{a}_{\mathbf{j}}$ & \multicolumn{1}{c}{$\mathbf{M P M}$} \\
\hline $\mathrm{Ca}^{2+}$ & $0.211 \pm 0.0031$ & $0.272 \pm 0.020$ & $0.226 \pm 0.0130$ \\
$\mathrm{Mg}^{2+}$ & $0.234 \pm 0.0011$ & $0.211 \pm 0.002$ & $0.215 \pm 0.0310$ \\
$\mathrm{Cu}^{2+}$ & $0.274 \pm 0.0032$ & $0.268 \pm 0.041$ & $0.265 \pm 0.0023$ \\
L-Alanine & - & - & $0.046 \pm 0.0031$ \\
Arginine & - & - & $0.022 \pm 0.0013$ \\
L-Cystine & - & - & $0.024 \pm 0.0023$ \\
Glucose & - & - & $0.123 \pm 0.0012$ \\
D-Fructose & - & - & $0.156 \pm 0.0041$ \\
Glycin & - & - & $0.135+0.0032$ \\
\hline
\end{tabular}

The suggested sensor was successfully utilized for acrylamide cations estimation in foodstuff samples with no pretreatment extraction as presented in Table 3. The data 
provided proved the practical validations of the technique as shown by the veracity, and preciseness statistical treatment of data.

Table 3. The recoveries of the added AA obtained by HPLC and by using the developed ion-selective electrode.

\begin{tabular}{|c|c|c|c|c|c|c|c|c|}
\hline \multirow[b]{2}{*}{ Foodstuff Sample } & \multirow{2}{*}{$\begin{array}{c}\text { AA } \\
\text { Added } \\
\mathrm{mg} \mathrm{Kg}^{-1}\end{array}$} & \multirow{2}{*}{$\begin{array}{c}\text { HPLC } \\
\text { Technique } \\
\begin{array}{c}\text { Recovery } \\
\pm \text { SD }^{\mathrm{a}}\end{array}\end{array}$} & \multicolumn{3}{|c|}{ Calibration Curve Method } & \multicolumn{3}{|c|}{ Standard Addition Method } \\
\hline & & & $\begin{array}{c}\text { AA } \\
\text { Found } \\
\mathrm{mg} \mathrm{Kg}^{-1}\end{array}$ & $\begin{array}{c}\text { Relative } \\
\text { Error } \\
\%\end{array}$ & $\begin{array}{c}\text { Recovery } \\
\pm \text { SD }^{\mathrm{a}}\end{array}$ & $\begin{array}{c}\text { AA } \\
\text { Found } \\
\mathrm{mg} \mathrm{Kg}^{-1}\end{array}$ & $\begin{array}{c}\text { Relative } \\
\text { Error } \\
\%\end{array}$ & $\begin{array}{c}\text { Recovery } \\
\pm \mathrm{SD}^{\mathrm{a}}\end{array}$ \\
\hline Roast Coffee (dry) & 200 & $99.55 \pm 0.25$ & 199.25 & 0.75 & $99.63 \pm 0.26$ & 195.15 & 4.85 & $97.57 \pm 0.35$ \\
\hline Instant(soluble) coffee & 350 & $99.65 \pm 0.16$ & 349.48 & 0.52 & $99.85 \pm 0.32$ & 346.03 & 3.97 & $98.86 \pm 0.65$ \\
\hline Potato chips & 375 & $99.75 \pm 0.23$ & 374.45 & 0.55 & $99.85 \pm 0.35$ & 371.06 & 3.94 & $98.94 \pm 0.54$ \\
\hline Crisp bread & 225 & $99.66 \pm 0.34$ & 224.55 & 0.45 & $99.80 \pm 0.56$ & 221.02 & 3.98 & $98.23 \pm 0.72$ \\
\hline French fries & 120 & $99.45 \pm 0.36$ & 119.12 & 0.82 & $99.26 \pm 0.45$ & 116.15 & 3.85 & $96.79 \pm 0.85$ \\
\hline Toast & 150 & $99.72 \pm 0.55$ & 149.54 & 0.46 & $99.69 \pm 0.35$ & 146.14 & 3.86 & $97.42 \pm 0.66$ \\
\hline Cearls based foods & 175 & $99.80 \pm 0.45$ & 174.35 & 0.65 & $99.62 \pm 0.31$ & 171.25 & 3.75 & $97.85 \pm 0.89$ \\
\hline
\end{tabular}

a The averages of (five) estimations.

Additionally, as can be seen from the provided data (Table 3) that the standard additions and the calibration curve techniques were applied. The treatment of the results illustrated that the technique of the calibration curve is recommended in the acrylamide detection while the standard additions technique is less recommended, the recorded error is not more than $0.82 \%$ and $4.85 \%$ in the two modes, respectively, which is due to the repeatability and veracity of the process.

The reproducibility of the proposed sensor was studied by a series of five membranes with the same composition and the response of these electrodes to acrylamide cations concentration was registered. The calibration curves were plotted to investigate the repeatability and reproducibility of the developed electrode. A similar electrode was applied during five replicate measurements for the repeatability test of the ion-selective electrode, while the responses of five similar electrodes to acrylamide cations concentration were tested for the reproducibility of the electrode in the concentration range of $1.0 \times 10^{-7}-1.0 \times 10^{-1} \mathrm{M}$ of acrylamide cations solutions. The results reveal that the standard deviation of measurements of $1.0 \times 10^{-1} \mathrm{M}$ to $1.0 \times 10^{-7} \mathrm{M}$ of acrylamide solution with these five sensors was $\pm 1.55 \mathrm{mV}$. The lower values of the coefficient of variation (0.38) also presented repeatability, reproducibility and the precision of the acrylamide selective electrode.

The provided results by the fabricated acrylamide sensor were treated statistically, compared to the other various previously published sensors. As can be seen in Table 4, a comparison among the interesting validation parameters of the quantitative estimations of acrylamide cations applying various electrodes listed recently in the literature. This comparison was made to prove whether the suggested sensor provides credible results and be assumptive for acrylamide cations in foodstuff samples. As displayed in Table 4, the suggested electrode offers a comparable linearity usable range $\left(1.0 \times 10^{-7}-1.0 \times 10^{-1} \mathrm{M}\right)$ which is more precious than the other recently published acrylamide selective electrodes [33-39]. It has a long lifetime (120 days) compared to the other listed sensors, which all have low limits of detection, the lowest is that stated in this developed research $\left(1.6 \times 10^{-8} \mathrm{M}\right)$. Furthermore, the proposed sensor has many advantages, is easy to construct, economical. Thus, it can be confidential to state that our suggested sensor is practically validated in all senses, with other sensors to estimate acrylamide cations concentration.

No considerable intervention was noticed from the constituents present in the samples under investigation. The calibration curves displayed an excellent linear restraint on an expanded linearity concentration range. Most of the techniques exhibit valuable veracity with regard to the real values, and no considerable difference for either veracity or preciseness was presented. 
Table 4. Comparison of the interesting validation parameters of acrylamide [BrPPSAA] with some published selective electrodes for acrylamide determination.

\begin{tabular}{|c|c|c|c|c|c|}
\hline Ref. & $\begin{array}{c}\text { Linear Range } \\
\text { (M) }\end{array}$ & $\begin{array}{l}\text { Response Time } \\
\text { (s) }\end{array}$ & $\begin{array}{l}\text { Longlife } \\
\text { (Day) }\end{array}$ & $\begin{array}{l}\text { Detection Limit } \\
\text { (M) }\end{array}$ & pH Range \\
\hline This work data & $1.0 \times 10^{-7}-1.0 \times 10^{-1}$ & 8 & 120 & $1.6 \times 10^{-8}$ & $3.0-6.5$ \\
\hline 33 & $7.0 \times 10^{-7}-7.0 \times 10-^{5}$ & - & 9 & $3.9 \times 10^{-5}$ & 7.4 \\
\hline 34 & $5.0 \times 10^{-4}-7.0 \times 10^{-4}$ & $<2$ & 100 & $2.0 \times 10^{-3}$ & 5.5 \\
\hline 35 & $1.0 \times 10^{-5}-1.0 \times 10^{-4}$ & $<2$ & 120 & $1.0 \times 10^{-5}$ & 5.0 \\
\hline 36 & $1.0 \times 10^{-5}-2.0 \times 10^{-4}$ & 10 & - & $3.0 \times 10^{-4}$ & - \\
\hline 37 & $4.0 \times 10^{-5}-2.0 \times 10^{-4}$ & 12 & 60 & $8.0 \times 10^{-9}$ & 4.5 \\
\hline 38 & $1.0 \times 10^{-8}-1.0 \times 10^{-5}$ & 10 & 60 & $4.0 \times 10^{-8}$ & \\
\hline 39 & $5.0 \times 10^{-9}-7.5 \times 10^{-4}$ & 20 & - & $2.0 \times 10^{-8}$ & 505 \\
\hline
\end{tabular}

\section{Conclusions}

A constructed acrylamide selective sensor was developed. The suggested electrode is specified by excellent validation parameters, such as short response time, relatively long lifetime and the specified Nernstian slope. The analytical validations of the examined sensor are summarized in Tables 1 and 2.

The developed sensor was applied to estimate acrylamide cations in foodstuff samples that were employed in general. The standard additions and the calibration curve techniques were employed. The statistical treatment of data provided that the calibration curve technique is better in the acrylamide estimation, while the standard additions technique is less acceptable. Thus, the error is not more than $1 \%$ because of the veracity, repeatability and reproducibility of the process. The mode of electrode construction was precise and accurate in comparison to the other previously listed techniques which are widely utilized in their estimation in foodstuff samples (Table 4).

In general, the quality of the produced data was excellent due to the optimum selection of the practical applications of the developed sensor. The consumed time in the determination is studied with no effect on the accuracy, and repeatability of the produced results.

Author Contributions: Software, M.E.-S. and A.E.-B.; formal analysis, M.E.-S. and A.E.-B.; resources, M.E.-S. and A.E.-B.; writing-original draft preparation, S.K. and A.E.-B.; writing-review and editing, S.K.; and supervision, S.K. All authors have read and agreed to the published version of the manuscript.

Funding: This research received no external funding.

Institutional Review Board Statement: Not applicable.

Informed Consent Statement: Not applicable.

Data Availability Statement: The data that support the findings of this study are available on request from the corresponding author.

Acknowledgments: This work was carried out using the facilities and materials in Taif University Researches Supporting Project number (TURSP-2020/139), Taif University, Taif, Saudi Arabia.

Conflicts of Interest: The authors declare no conflict of interest.

\section{References}

1. Pundir, C.S.; Yadav, N.; Chhillar, A.K. Occurrence, synthesis, toxicity and detection methods for acrylamide determination in processed foods with special reference to biosensors. Trends Food Sci. Technol. 2019, 85, 211-225. [CrossRef]

2. Omar, M.M.A.; Elbashir, A.A.; Schmitz, O.J. Capillary electrophoresis method with UV-detection for analysis of free amino acids concentrations in food. Food Chem. 2017, 214, 300-307. [CrossRef]

3. Alpözen, E.; Guven, G.; Özdestan, Ö.; Üren, A. Determination of acrylamide in three different bread types by an in-house validated LC-MS/MS method. Acta Alimentaria 2015, 44, 211-220. [CrossRef]

4. Beckett, J.M.; Ball, M.J. Effect of hereditary haemochromatosis genotypes and iron overload on other trace elements. Eur. J. Nutr. 2012, 52, 255-261. [CrossRef] [PubMed]

5. Kazemi, F.; Zamani, H.A.; Joz-Yarmohammadi, F.; Ebrahimi, M.; Abedi, M.R. Potentiometric studies of a new solid-state contact iron (III)ion selective electrode. Bul. Chem. Commun. 2017, 49, 449-456. 
6. Mecheri, N.; Benounis, M.; Barhoumi, H. New modified selective platinum electrode based on poly (ethylene glycol) for Iron (III) detection in real water. Sens. Rev. 2017, 37, 436-443. [CrossRef]

7. Takatsuki, S.; Nemoto, S.; Sasaki, K.; Maitani, T. Determination of acrylamide in processed foods by LC/MS using column switching. Shokuhin Eiseigaku Zasshi 2003, 44, 89-95. [CrossRef]

8. Omar, M.M.A.; Ibrahim, W.A.W.; Elbashir, A.A. Sol-gel hybrid methyl trimethoxysilane-tetraethoxysilane as a new dispersive solid-phase extraction material for acrylamide determination in food with direct gas chromatography-mass spectrometry analysis. Food Chem. 2014, 158, 302-309. [CrossRef] [PubMed]

9. Wu, J.H.; Zhao, H.B.; Du, M.; Song, L.; Xu, X.B. Dispersive liquid-liquid microextraction for rapid and inexpensive determination of tetramethylpyrazine in vinegar. Food Chem. 2019, 286, 141-145. [CrossRef] [PubMed]

10. Singh, G.; Brady, B.; Koerner, T.B.; Becalski, A.; Zhao, T.; Feng, S. Development of a highly sensitive competitive indirect enzyme-linked immunosorbent assay for detection of acrylamide in foods and water. Food Anal. Chem. 2014, 7, 1298-1304. [CrossRef]

11. Alahari, A.; Trivelli, X.; Guérardel, Y.; Dover, L.G.; Besra, G.S.; Sacchettini, J.C.; Reynolds, R.C.; Coxon, G.D.; Kremer, L. Thiacetazone, an antitubercular drug that inhibits cyclopropanation of cell wall mycolic acids in mycobacteria. PLoS ONE 2007, 2, e1343. [CrossRef] [PubMed]

12. Safavi, A.; Maleki, N.; Farjami, E.; Mahyari, F.A. Simultaneous electrochemical determination of glutathione and glutathione disulfide at a nanoscale copper hydroxide composite carbon ionic liquid electrode. Anal. Chem. 2009, 81, 7538-7543. [CrossRef] [PubMed]

13. Beitollahi, H.; Maleh, H.K.; Khabazzadeh, H. Nanomolar and selective determination of epinephrine in the presence of norepinephrine using carbon paste electrode modified with carbon nanotubes and novel 2-(4-oxo-3 -phenyl-3,4-dihydro-quinazolinyl)N'-phenyl-hydrazinecarbothioamide. Anal. Chem. 2008, 80, 9848-9851. [CrossRef] [PubMed]

14. Beitollahi, H.; Dourandish, Z.; Tajik, S.; Ganjali, M.R.; Norouzi, P.; Faridbod, F. Application of graphite screen printed electrode modified with dysprosium tungstate nanoparticles in voltammetric determination of epinephrine in the presence of acetylcholine. J. Rare Earths 2018, 36, 750-757. [CrossRef]

15. Ganjali, M.R.; Beitollahi, H.; Zaimbashi, R.; Beitollahi, H.; Rezapour, M.; Larijani, B. Voltammetric determination of dopamine using glassy carbon electrode modified with $\mathrm{ZnO} / \mathrm{Al} 2 \mathrm{O} 3$ nanocomposite. Int. J. Electrochem. Sci. 2018, 13, 2519-2529. [CrossRef]

16. Ganjali, M.R.; Dourandish, Z.; Beitollahi, H.; Tajik, S.; Hajiaghababaei, L.; Larijani, B. Highly sensitive determination of theophylline based on graphene quantum dots modified electrode. Int. J. Electrochem. Sci. 2018, 13, 2448-2461. [CrossRef]

17. Motaghi, M.M.; Beitollahi, H.; Tajik, S.; Rahma, H. Nanostructure electrochemical sensor for voltammetric determination of vitamin C in the presence of vitamin B6: Application to real sample analysis. Int. J. Electrochem. Sci. 2016, 11, 7849-7860. [CrossRef]

18. Soltani, H.; Beitollahi, H.; Mehrjardi, A.H.; Tajik, S.; Mahani, M.T. Voltammetric determination of glutathione using a modified single walled carbon nanotubes paste electrode. Anal. Bioanal. Electrochem. 2014, 6, 67-79.

19. Shawish, H.M.A.; Ghalwa, N.A.; Saadeh, S.M.; Aeen, H.H. Development of novel potentiometric sensors for determination of tartrazine dye concentration in foodstuff products. Food Chem. 2012, 138, 126-132. [CrossRef]

20. Shawish, H.M.A.; Habiby, M.; Aziz, H.S.A.; Saadeh, S.M.; Thaz, A. Determination of trihexyphenidyl hydrochloride drug in tablets and urine using a potententiometric carbon paste electrode. Sens. Actuators B Chem. 2016, 235, 18-26. [CrossRef]

21. Saadeh, S.M.; Shawish, H.A.; Dalloul, H.M.; El-Halabi, N.M.; Daher, B.K. Lead(II) complexes with some SNO and ONO tridentate Schiff base ligands and their evaluation as lead(II) sensors. Mater. Sci. Eng. C 2012, 32, 619-624. [CrossRef]

22. Vercelli, B.; Crotti, S.; Agostini, M. Voltammetric responses at modified electrodes and aggregation effects of two anticancer molecules. New J. Chem. 2020, 44, 18233-18241. [CrossRef]

23. Shetti, N.B.; Mishra, A.; Basu, S.; Mascarenhas, R.J.; Kakarla, R.R.; Aminabhavi, T.M. Skin-Patchable electrodes for biosensor applications. ACS Biomater. Sci. Eng. 2020, 6, 1823-1835. [CrossRef]

24. Bakker, E.; Buhlmann, P.; Pretsch, E. Carrier-based ion-selective electrodes and bulk optodes. Chem. Rev. 1997, 97, 3083-3132. [CrossRef]

25. Baghbamidi, S.E.; Beitollahi, H.; Tajik, S.; Zadeh, R.H. Voltammetric sensor based on 1-benzyl-4-ferrocenyl-1H-[1,2,3]triazole/carbon nanotube modified glassy carbon electrode; detection of hydrochlorothiazide in the presence of propranolol. Int. J. Electrochem. Sci. 2016, 11, 10874-10883. [CrossRef]

26. Beitollahi, H.; Tajik, S. Construction of a nanostructure-based electrochemical sensor for voltammetric determination of bisphenol A. Environ. Monit. Assess. 2015, 187, 257-265. [CrossRef]

27. Gupta, V.K.; Maleh, H.K.; Sedegh, R. Simultaneous determination of hydroxyl amine, phenol and sulfite in water and waste water samples using a voltammetric nano sensor. Int. J. Electrochem. Sci. 2015, 10, 303-316.

28. Sekar, K.; Gupta, V.K.; Ramasamy, B.; Titus, A. A new approach for the degradation of high concentration of aromatic amine by hetero catalytic Fenton oxidation: Kinetic and spectroscopic studies. J. Mol. Liq. 2012, 173, 153-163.

29. Gupta, V.K.; Margu, N.; Kumawat, L.K.; Singh, A.K. Selective naked-eye detection of magnesium (II) ions using a coumerinderived fluorescent probe. Sens. Actuators B Chem. 2015, 207, 216-223. [CrossRef]

30. Goyal, R.N.; Gupta, V.K.; Sangal, A.; Bachheti, N. Voltammetric determination of uric acid at a fullerence-C60-modified glassy carbon electrode. Electroanalysis 2005, 17, 2217-2223. [CrossRef] 
31. Gupta, V.K.; Margu, N.; Kumawat, L.K.; Singh, A.K. A reverseible fluorescence "off-on-off" sensor for sequential detection of aluminum and acetate/fluoride ions. Talanta 2015, 144, 80-89. [CrossRef]

32. Gupta, V.K.; Singh, A.K.; Kumawat, L.K. Thiazole Schiff base turn-on fluorescent chemosensor for Al3+ ion. Sens. Actuators B Chem. 2014, 195, 98-108. [CrossRef]

33. Xia, L.; Lu, G.M.; Yuan, L.W.; Xing, B.S.; Yan, L.; Yang, Y. Electrochemical sensor based on imprinted Sol-Gel polymer on Au NPs-MWCNTs-CS modified electrode for the determination of acrylamide. Food Anal. Methods 2016, 9, 114-121.

34. Batra, B.; Lata, S.; Pundir, C.S. Construction of an improved amperometric acrylamide biosensor based on hemoglobin immobilized onto carboxylated multi-walled carbon nanotubes/iron oxide nanoparticles/chitosan composite film. Bioprocess Biosyst. Eng. 2013, 36, 1591-1599. [CrossRef] [PubMed]

35. Yadav, N.; Chhillar, A.K.; Pundir, C.S. Characterization and application of haemoglobin nanoparticles for detection of acrylamide in processed foods. Int. J. Biol. Macromol. 2018, 107, 1000-1013. [CrossRef]

36. Fuentes, F.J.G.; Manriquez, J.M.; Godínez, L.A.; Escarpa, A.; Mendoza, S. Electrochemical analysis of acrylamide using screenprinted carboxylated single-walled carbon nanotube electrodes. Electroanalysis 2014, 26, 1039-1044. [CrossRef]

37. Huang, S.; Lu, S.; Huang, C.; Sheng, J.; Zhang, L.; Su, W. An electrochemical biosensor based on single-stranded DNA modified gold electrode for acrylamide determination. Sens. Actuators B Chem. 2016, 224, 22-30. [CrossRef]

38. Garabagiu, S.; Mihailescu, J. Simple hemoglobin-gold nanoparticles modified electrode for the amperometric detection of acrylamide. J. Electroanal. Chem. 2011, 659, 196-200. [CrossRef]

39. Batra, B.; Lata, S.; Sharma, S.; Pundir, C.S. An acrylamide biosensor based on immobilization of hemoglobin onto multi-walled carbon nanotube/copper nanoparticles/polyaniline hybrid film. Anal. Biochem. 2013, 433, 210-217. [CrossRef]

40. Li, N.; Liu, X.; Zhu, J.; Zhou, B.; Jing, J.; Wang, A.; Xu, R.; Wen, Z.; Shi, X.; Guo, S. Simple and sensitive detection of acrylamide based on hemoglobin immobilization in carbon ionic liquid paste electrode. Food Control 2020, 109. [CrossRef]

41. Gupta, V.K.; Singh, L.P.; Sing, B. A novel copper (II) selective sensor based on dimethyl(o-phenylene) bis(3-thioalloophanate) in PVC matrix. J. Mol. Liq. 2012, 174, 11-16. [CrossRef]

42. Gupta, V.K.; Kumar, S.; Singh, L.P.; Shoora, S.; Sethi, B.K. Cadmium (II) ion sensing through p-tert-butyl calix[6] arene based potentiometric sensor. J. Mol. Liq. 2014, 195, 65-68. [CrossRef]

43. Yola, M.L.; Gupta, V.K.; Eren, T.; Sen, A.E.; Atar, N. A novel electroanalytical nano sensor based on graphene oxide/silver nanoparticles for simultaneous determination of quercetin and morin. Electrochimica Acta 2014, 120, 204-211. [CrossRef]

44. Alil, I.; Gupta, V.K.; Khan, T.A.; Asim, M. Removal of arsenate from aqueous solution by electro-coagulation method using Al-Fe electrodes. Int. J. Electrochem. Sci. 2012, 7, 1898-1907.

45. Ahmed, F.A. Spectrophotometric determination of cobalt in biological and environmental samples using 2, 6-pyridinedicarboxaldehyde thiosemicarbazone. Int. J. Anal. Pharm. Bio. Sci. 2013, 2, 6-12.

46. Basha, V.S.; Chowdary, P.G.; Renuka, M. Non-Extractive Spectrophotometric Determination of Cobalt (II) using 2-Acetylthiophene Isonico tinoylhydrazone in Environmental and Pharmaceutical Samples. J. Pharma. Drug Res. 2019, 2, 102-109.

47. Sulaiman, S.T.; Hamoudi, T.A. Spectrophotometric Determination of Cobalt(II) with Mordant Blue 9-Application to Vitamin B12 (Injections and Powder). Raf. J. Sci. 2018, 27, 93-100.

48. Kuliyev, K.A.; Verdizadeh, N.A.; Suleymanova, G.S. Spectrophotometric Determination of Cobalt (II) with 2, 6-Dithiolphenol and Its Derivatives in the Presence of Hydrophobic Amines. Am. J. Chem. 2016, 6, 95-101.

49. Makino, T.; Sainto, M.; Horiguchi, D.; Kina, K.; Wilairat, P. A highly sensitive colorimetric determination of serium zinc using water-soluble pyridylazo dye. Clin. Chim. Acta 1982, 120, 127-133. [PubMed]

50. Pengyan, L.; Zhang, L.; Liu, L. Determination of acrylamide using high performance liquid chromatographic method. Chem. J. Internet 2008, 10, 9-16.

51. Khalil, S.; Harthi, S.S.A. Ion-selective Membrane Sensor for Magnesium Determination in Pharmaceutical Formulations. Int. J. Electrochem. Sci. 2020, 15, 9223-9231. [CrossRef]

52. Gadzekpo, V.Y.P.; Christian, G.D. Determination of selectivity coefficients of ion-selective electrodes. Anal. Chim. Acta 1984, 164, 279-282. [CrossRef]

53. Panggabean, A.S. Preparation and characterization ion selective electrode Cd(ii) based on chitosan in PVC membrane. Indones. J. Chem. 2011, 11, 285-289. [CrossRef]

54. Khalil, M.M.; Issa, Y.M.; Zayed, S.I.M.; Mohamed, N.A. Improved determination of pinaverium bromide in pharmaceutical preparations and human urine utilizing a coated wire electrode. Int. J. Adv. Res. 2015, 6, 638-652. 